\title{
Acquisition of instrumental responding following noncontingent reinforcement: Failure to observe "learned laziness" in rats
}

\author{
WILLIAM W. BEATTY and WILLIAM S. MAKI \\ North Dakota State University, Fargo, North Dakota 58105
}

\begin{abstract}
Two experiments examined the possibility that presenting hungry rats with noncontingent food would interfere with the acquisition of instrumental responding for food reward. In Experiment 1 groups of rats received 0, 1, 10, or 20 50-min sessions, during which Noyes pellets were presented noncontingently on a variable time (VT) 60 -sec schedule, and were subsequently trained to barpress for food reward. All three groups that received noncontingent food acquired instrumental responding for food reward more rapidly than the 0 -session controls, but there was no indication that 10 or 20 sessions of exposure to noncontingent food produced slower acquisition of the instrumental response than 1 session. In Experiment 2 two groups were exposed to 1 or 30 1-h sessions, with food delivered on a VT 60 -sec schedule. A third group lived $24 \mathrm{~h} /$ day in operant chambers for 15 days; food was delivered noncontingently on a V'T 6-min schedule throughout the day. The latter group was then given a single 1-h session in the test chamber with food delivered noncontingently on a VT 60-sec schedule. During tests of instrumental responding for food, all three groups acquired the barpress response at similar rates. The present experiments fail to confirm earlier reports that prior exposure to noncontingent food impairs subsequent acquisition of food-rewarded responding by rats.
\end{abstract}

Delivery of food to a hungry pigeon on a schedule unrelated to the animal's behavior retards subsequent acquisition of autoshaped keypecking or treadlepress responding (Engberg, Hansen, Welker, \& Thomas, 1972; Welker, 1976). This phenomenon, termed "learned laziness" by Engberg et al., has been linked theoretically to "learned helplessness" (Maier \& Seligman, 1976), which is evidenced by retarded escape learning following exposure to noncontingent shock. Seligman (1975) and Wheatley, Welker, and Miles (1977) reported that deficits in instrumental responding for food could also be observed in rats given prior exposure to noncontingent food, but methodological difficulties exist in both of these studies. Seligman (1975) provided very few procedural details about his experiment, and there are errors in the statistical analysis of the Wheatley et al. study; in fact, differences in instrumental performance between their noncontingently reinforced and control groups were not significant (Wheatley, Welker, \& Miles, 1978). So, in the present experiments, we reexamined the influence of varying amounts of prior noncontingent reinforcement on the acquisition of instrumental barpressing for food reward in rats.

We thank James C. Moe for his enthusiastic assistance in the early stages of this research. Requests for reprints should be sent to W. W. Beatty, Department of Psychology, North Dakota State University, Fargo, North Dakota 58105.

\section{EXPERIMENT 1}

\section{Method}

Subjects. The subjects were 27 naive male Holtzman rats that weighed $300-350 \mathrm{~g}$ at the start of the experiment. They were caged singly with free access to water in a temperatureregulated $\left(23^{\circ} \mathrm{C} \pm 3^{\circ} \mathrm{C}\right)$ room that was illuminated from $0800 \mathrm{~h}$ to $2000 \mathrm{~h}$. Behavioral tests occurred during the light portion of the day-night cycle. The rats were maintained at $80 \%-85 \%$ of their free-feeding weights throughout the experiment.

Apparatus. Training and testing were conducted in three identical BRS/LVE 143-22 operant conditioning chambers (24.1 $\times 30.5 \times 24.1 \mathrm{~cm}$ high). The standard chambers were modified by removing the response lever on the right side of the front panel, leaving a single lever $(3.8 \times 1.9 \mathrm{~cm})$ centered $5.0 \mathrm{~cm}$ from the corner and $7.8 \mathrm{~cm}$ above the grid floor. This manipulandum protruded $2.9 \mathrm{~cm}$ into the chamber and required $12 \mathrm{~g}$ to operate the microswitch associated with the lever. The pellet delivery chute was centered on the front panel $2.0 \mathrm{~cm}$ above the floor and $7.0 \mathrm{~cm}$ to the right of the response lever. A single panel light located $6.5 \mathrm{~cm}$ above the lever was illuminated during all training and testing sessions. An Automated Data Systems $1800 \mathrm{E}$ lab computer controlled delivery of reinforcers (45-mg Noyes pellets) and recorded performance.

Procedure. The rats were assigned at random to groups that received $0(\mathrm{~N}=6), 1(\mathrm{~N}=7), 10(\mathrm{~N}=6)$, or $20(\mathrm{~N}=8) 50$-min pretraining sessions, during which food pellets were delivered on a variable time (VT) 60-sec schedule. To preclude the possibility that random barpresses might be adventitiously reinforced, an additional constraint was imposed: Scheduled reinforcers occurred only after $10 \mathrm{sec}$ during which no responses occurred. All groups were exposed to food deprivation for the same amount of time ( 25 days); testing occurred on the same day, the day following the last pretraining session for all groups.

On the test day animals were initially placed in the chamber, 
with the response lever baited with a single $45-\mathrm{mg}$ Noyes pellet. The time required to earn 60 pellets and the last 50 pellets was recorded with reward available on a fixed ratio (FR) 3 schedule.

While not originally planned, the animals were "tested" again 14 days after the original test session during the course of retraining for service in an unrelated experiment. After the first test session, all rats were maintained with unrestricted access to food in their home cages. They were then deprived again prior to the second test. This delayed test session was conducted just as the first test session, but the only data recorded were times taken to earn 60 reinforcers.

\section{Results}

As shown in Table 1, all of the groups that received pretraining with noncontingent delivery of food acquired barpressing for contingent reward more rapidly than the control group. Analysis of the time required to earn 60 pellets revealed a significant treatment effect $[F(3,23)=35.73, p<.001]$. Subsequent comparisons indicated that the three pretrained groups combined acquired their 60 pellets faster than did the control group $[F(1,23)=106.4, p<.001]$, but did not differ among themselves $(F<1)$. Analysis of time required to earn the last 50 pellets revealed essentially the same pattern with one exception: Animals in the 20-day condition earned the last 50 pellets more rapidly than did animals in the 1-day group $[F(1,13)=9.55$, $\mathrm{p}<.01]$.

During the second test session, mean times to earn 60 pellets were $21.8,13.7,12.0$, and $10.7 \mathrm{~min}$ for the groups originally exposed to $0,1,10$, and 20 days of pretraining, respectively. Planned comparisons revealed that the three pretrained groups combined completed the test session significantly faster than did the control group $[F(1,23)=12.12, p<.01]$. The three pretrained groups also differed from each other, unlike during the first test session $[F(2,18)=3.56, p<.05]$. Subsequent tests revealed that the 1- and 10-day groups were significantly slower than the 20-day group $[F(1,18)=4.84, p<.05]$, but did not differ from each other $[F(1,11)=1.83]$.

Barpressing during the pretraining sessions by the groups given 10 or 20 days of pretraining declined over the first 10 sessions from a mean of 85 responses/h to an average of 22 responses/h. During Sessions 11-20, low rates of responding (averaging 11 responses/h) were maintained by the animals in the 20-day group. The operant level on the single session for the 1-day group

Table 1

Acquisition of Barpressing as a Function of Amount of Exposure to Noncontingent Food

\begin{tabular}{ccc}
\hline \multirow{2}{*}{$\begin{array}{c}\text { Pretraining } \\
\text { Sessions }\end{array}$} & \multicolumn{2}{c}{ Time (in Minutes) to Earn } \\
\cline { 2 - 3 } 60 Pellets & Last 50 Pellets \\
\hline 0 & 36.7 & $20.7^{*}$ \\
1 & 14.6 & 7.9 \\
10 & 13.1 & 6.9 \\
20 & 15.1 & 6.3 \\
\hline
\end{tabular}

Note-Data were lost for one subject. was comparable to that on the initial session of the other groups given pretraining ( 80 responses/h).

\section{EXPERIMENT 2}

In Experiment 1 animals that received approximately 500 or 1,000 deliveries of noncontingent food learned to barpress for food as rapidly as rats given only 50 such presentations, and all three groups learned more rapidly than animals given no magazine training at all. While those results certainly fail to demonstrate learned laziness, it could be argued that 500 or even 1,000 noncontingent pellets, even when presented in the same context as the subsequent learning tests, are not enough to produce interference. The second experiment addressed this question by examining instrumental responding after greater amounts of exposure to noncontingent food. One group received 1,800 pellets, delivered in the same context as the instrumental learning. A second group was given approximately 3,500 pellets in a slightly different context (a different operant chamber). The latter group provided a systematic replication of the "response-independent" condition in the study by Wheatley et al. (1977).

\section{Method}

Thirty adult male rats were obtained from the Holtzman Company, Madison, Wisconsin, at about 4 months of age. Housing, deprivation, and general maintenance procedures were identical to those of Experiment 1 . The rats were assigned at random to one of three groups. The 1-day group $(\mathrm{N}=9)$ was given a single 60 -min session of exposure to noncontingent food delivered on a VT 60-sec schedule in the BRS/LVE chambers described earlier. The 30 -day group $(\mathrm{N}=9)$ received $3060-\mathrm{min}$ sessions, identical to the single session given to the rats in the 1-day group, also in the BRS/LVE chambers. The "live-in lazy" group (LIL, $N=12$ ) spent $24 \mathrm{~h} /$ day for 15 days housed in conventional Gerbrands operant conditioning chambers; the chambers were equipped with the manufacturer-supplied response lever, feeder, and cue light mounted in the stock positions. A water bottle and drinking tube were mounted on the wall of the chamber, providing the rats with free access to water throughout each day. The rats in the LIL group were removed from the chambers for a few minutes and weighed once a day; at that time chunks of Purina Lab Chow were placed in the chambers in sufficient quantities to maintain the rats at about $85 \%$ of their free-feeding weights. During this period 45-mg pellets were delivered on a VT 6-min schedule throughout the day; the animals received an average of 235 pellets/day delivered noncontingently. On the last (15th) day of treatment, the animals in the LIL group averaged $87 \%$ of their free-feeding weights (range: 83\%-93\%). For the next 3 days, these animals were housed in their home cages so as to stabilize body weights at about $85 \%$. On the following day, the LIL rats received one 60-min session of pretraining in the BRS/LVE chambers, during which $45-\mathrm{mg}$ pellets were delivered noncontingently on a VT 60 -sec schedule as for the other groups. During these parts of the experiment, barpressing was recorded, but responses were ineffectual. Unlike in Experiment 1, however, barpresses that occurred within $10 \mathrm{sec}$ of a scheduled pellet delivery did not postpone the pellet.

During the final day of the experiment, all rats were tested for acquisition of instrumental responding. The procedures and apparatus (the BRS/LVE chambers) were the same as in Experiment 1 except that the bar was not baited at the outset of 
Table 2

Times to Acquire Barpressing as a Function of Amount and Type of Exposure to Noncontingent Food

\begin{tabular}{|c|c|c|c|}
\hline \multirow[b]{2}{*}{ Group } & \multicolumn{3}{|c|}{ Mean Time (in Minutes) to Earn } \\
\hline & 60 Pellets & $\begin{array}{c}\text { First } \\
10 \text { Pellets }\end{array}$ & $\begin{array}{c}\text { Last } \\
50 \text { Pellets } \\
\end{array}$ \\
\hline 1 day & 18.2 & 9.6 & 8.6 \\
\hline 30 day & 20.1 & 12.9 & 7.2 \\
\hline ILIL & 19.3 & 8.6 & 10.8 \\
\hline
\end{tabular}

testing. As in Experiment 1, a FR 3 schedule was in effect, and testing continued until the rat earned 60 reinforcers.

\section{Results}

Table 2 depicts the results of Experiment 2. Analysis of the time to earn 60 pellets revealed no reliable effect of treatment $(F<1)$. Likewise, analysis of the time to earn the first 10 pellets disclosed no significant differences among groups $[F(2,27)=1.52]$, and, in any event, the LIL group met this criterion somewhat more rapidly than did the 1-day magazine training controls. Only for the time to earn the last 50 pellets was a treatment effect observed $[F(2,27)=3.82, p<.05]$, but subsequent tests demonstrated that the only significant difference was between the LIL and 30-day groups $[t(19)=2.69, p<.05]$. Neither of these two groups significantly differed from the 1-day group [for LIL vs. 1 day, $t(19)=1.65$; for 30 day vs. 1 day, $t(16)=.96]$.

During the pretraining phase of the experiment, barpressing generally declined from the first to the last day of noncontingent feeding. For the LIL group, all 12 subjects showed this pattern and the overall decline (mean responses $/$ day $=376$ vs. 13 ), although variable across subjects, was reliable ( $p<.001$ by a sign test). Animals in the 30-day group showed a similar trend (mean responses $/ \mathrm{h}=72$ vs. 47 ), but the difference was not significant $[F(1,8)=3.85]$. Analysis of the number of responses made on the last day of pretraining in the BRS/LVE chambers (the magazine training day for the 1 -day and LIL groups), however, revealed no reliable group differences $[\mathrm{F}(2,27)=2.19]$.

\section{DISCUSSION}

In contrast to earlier reports (Seligman, 1975; Wheatley et al., 1977), we found no evidence that prior exposure to as many as 3,500 noncontingent food pellets retarded acquisition of instrumental barpressing for food reward. Using a triadic (yoked-control) design, Wheatley et al. reported that rats trained to make an instrumental nose-poking response (responsedependent group) learned to barpress for food more rapidly than controls that were merely housed in the chambers; controls in turn learned to barpress more rapidly than rats in the response-independent group that were fed every time their response-dependent mates earned reinforcers. However, a reanalysis of the data indicated that the crucial difference between the control and response-independent groups was not significant (Wheatley et al., 1978). But assume for the moment that the trends reported by Wheatley et al. (1977) are reliable. It then becomes of interest to explore possible reasons for the different outcomes.

There are at least four procedural differences between Experiment 2 of the present study and that of Wheatley et al. (1977), but it is not clear why these differences should account for the discrepancies in results. First, we delivered noncontingent food on a VT schedule, while Wheatley et al. used a yokedcontrol procedure, but there is no reason to believe that this should matter assuming that noncontingent delivery of food, like delivery of uncontrollable shock, induced a cognitive state of helplessness, as Seligman and his colleagues have argued (e.g., Maier \& Seligman, 1976; Seligman, 1975). Clearly, VT schedules of inescapable shock can lead to deficits in instrumental escape behavior in rats (e.g., Maier, Albin, \& Testa, 1973; Seligman, Rosellini, \& Kozak, 1975). Second, our rats were exposed to noncontingent food in the presence of a response bar identical or at least similar to the manipulandum used in the instrumental tests, while no lever was present during noncontingent food delivery in the Wheatley et al. (1977) study. It seems to us that our procedure would have increased the chances of observing an impairment in the acquisition of barpressing because the rats could have learned that a specific response during pretraining was ineffective (regardless of the possible acquisition of a generalizable cognitive set). Such learning might have been especially likely in our first experiment, where contingencies were arranged so that barpressing and the delivery of food were actually negatively correlated in pretraining to preclude adventitious reinforcement of barpressing. Despite these features of our procedure, no impairment was observed. Third, we used a FR 3 schedule during acquisition, while Wheatley et al. used FR 1. Based on previous research on instrumental escape behavior in rats (e.g., Maier et al., 1973; Seligman \& Beagley, 1975) as well as treadlepressing in pigeons (Welker, 1976), our use of a FR 3 schedule should have increased the probability of detecting an interference effect by prior exposure to unpredictable and uncontrollable events. Finally, the rats in the LIL group in Experiment 2 received treatment and testing in different contexts; such changes in context are known to attenuate the detrimental effects of noncontingent rewards on autoshaping (Tomie, 1976). However, in both Experiments 1 and 2 (the 30-day group), no effect of noncontingent reward was seen when the contexts remained the same between training and testing. Thus, the necessary conditions for producing retarded instrumental acquisition in rats following experience with noncontingent food remain unknown.

\section{REFERENCES}

Engberg, L. H., Hansen, G., Welker, R. L., \& Thomas, D. R. Acquisition of key-pecking via autoshaping as a function of prior experience: "Learned laziness?" Science, 1972, 178, 1002-1004.

Maier, S. F., Albin, R. W., \& Testa, T. J. Failure to learn to escape in rats previously exposed to inescapable shock depends on the nature of the escape response. Journal of Comparative and Physiological Psychology, 1973, 85, 581-592.

Maier, S. F., \& Seligman, M. E. P. Learned helplessness: Theory and evidence. Journal of Experimental Psychology: General, 1976, 105, 3-46.

Seligman, M. E. P. Helplessness: On depression, development, and death. San Francisco: Freeman, 1975.

Seligman, M. E. P., \& Beagley, G. Learned helplessness in the rat. Journal of Comparative and Physiological Psychology, 1975, 88, 534-541.

Seligman, M. E. P., Rosellini, R. A., \& Kozak, M. J. Learned helplessness in the rat: Time course, immunization, and rever- 
sibility. Journal of Comparative and Physiological Psychology, $1975,88,542-547$.

Tomie, A. Retardation of autoshaping: Control by contextual stimuli. Science, 1976, 192, 1244-1246.

WelKer, R. L. Acquisition of a free-operant-appetitive response in pigeons as a function of prior experience with responseindependent food. Learning and Motivation, 1976, 7, 394-405.

Wheatley, K. L., Welker, R. L., \& Miles, R. C. Acquisition of barpressing in rats following experience with response- independent food. Animal Learning \& Behavior, 1977, 5, 236-242.

Wheatley, K. L., Welker, R. L., \& Miles, R. C. Acquisition of barpressing in rats following experience with responseindependent food. Animal Learning \& Behavior, 1977, 5. 236-242. (Erratum, 1978, 6, 51.)

(Received for publication January 16, 1979.) 